\title{
On the Possible Contribution of Natural Climatic Fluctuations to the Global Warming of the Last 135 Years
}

\author{
Maxim Ogurtsovi,2, Markus Lindholm³ ${ }^{3}$, Risto Jalkanen ${ }^{3}$ \\ ${ }^{1}$ Ioffe Physico-Technical Institute, Russian Academy of Sciences, St. Petersburg, Russia \\ ${ }^{2}$ General Astronomical observatory at Pulkovo, St. Petersburg, Russia \\ ${ }^{3}$ Natural Resources Institute Finland (Luke), Rovaniemi, Finland \\ Email: maxim.ogurtsov@mail.ioffe.ru
}

How to cite this paper: Ogurtsov, M., Lindholm, M. and Jalkanen, R. (2017) On the Possible Contribution of Natural Climatic Fluctuations to the Global Warming of the Last 135 Years. Atmospheric and Climate Sciences, 7, 256-262.

http://dx.doi.org/10.4236/acs.2017.73018

Received: March 31, 2017

Accepted: July 1, 2017

Published: July 4, 2017

Copyright $\odot 2017$ by authors and Scientific Research Publishing Inc. This work is licensed under the Creative Commons Attribution International License (CC BY 4.0). http://creativecommons.org/licenses/by/4.0/

\section{Open Access}

\begin{abstract}
A number of numerical experiments with artificial random signals (the second order autoregressive processes), which have important statistical properties similar to that of the observed instrumental temperature (1850-2015), were carried out. The results show that in frame of the selected mathematical model the return period of climatic events, analogous to the current global warming (linear increase of temperature for $0.95^{\circ} \mathrm{C}$ during the last 135 years) is 2849-5180 years (one event per 2849-5180 years). This means that global warming $(\mathrm{GW})$ of the last 135 years can unlikely be fully explained by inherent oscillations of the climatic system. It was found however, that natural fluctuations of climate may appreciably contribute to the GW. The return period of climatic episodes with $0.5^{\circ} \mathrm{C}$ warming during the 135 years (half of the observed GW) was less than 500 years. The result testifies that the role of external factors (emission of greenhouse gases, solar activity etc.) in the GW could be less than often presumed.
\end{abstract}

\section{Keywords}

Global Warming, Climate, Natural Oscillations

\section{Introduction}

It is generally well-known that the mean surface temperature of the globe has been rising during more than last century [1] [2]. It is widely accepted also that this GW is caused primarily by anthropogenic increase of greenhouse gases concentration [1] [2]. However debates on this question still continue. Some experts maintain that current warming does not exceed the natural fluctuations of 
climate. Evidence of appreciable contribution to GW of non-greenhouse factors has been obtained by many authors. E.g. Soon et al. [3] noted that if the urbanization effect is properly taken into account, one can conclude that solar variability is the dominant factor of Northern Hemisphere long-term temperature changes since at least 1881. Zhao and Feng [4] reported that variations in solar activity play an important role in changes of climate over global scale during the last more than 100 years. According to Harde [5] the Sun is the main contributor to global warming of the last century. Lüdecke et al. [6] showed that variations of Central European temperature after 1757 were likely governed by periodic oscillations resulted from intrinsic climatic dynamics. Scafetta [7] [8] claimed that the global climate oscillations from 1950 to 2011 were appreciably influenced by astronomic planetary cycles, particularly by motion of Jupiter and Saturn. Swanson and Tsonis [9] noted that in the period 1900-2000 Northern Hemisphere climate variability might be partly explained by chaotic dynamics. Privalsky and Fortus [10] modeled variations of global temperature during 18502009 as an autoregressive process of the fourth order. They arrived at a conclusion that GW of the last 150 years could be fully explained by natural climatic variability without any external forcing. In the present work we continue research of possible contribution of intrinsic variations of climatic system to the GW.

\section{Modeling of the Changes of the Global Temperature during the Last 135 Years}

Privalsky and Fortus [10] modeled variations of the global temperature as a random autoregressive process:

$$
\Delta T^{m}(t)=\sum_{j=1}^{p} \varphi_{j} \Delta T^{m}(t-j)+\varepsilon_{j},
$$

where $\varepsilon_{j}$ is a zero mean white noise and values of $p=4$ and autoregressive coefficients $\phi_{j}$ were determined in order to obtain Fourier spectrum of the modeled signal coincides with the spectrum of the actual instrumental series (1850-2009). It should be noted, however, that the length of experimental temperature record is too short for accurate estimation of spectral power over the low-frequency domain (periods longer than 40 - 50 years). Here we follow the approach of [10] but with substantial changes:

1) We used data on instrumental temperature anomaly $\Delta T$ over $1880-2015$ (http://cdiac.ornl.gov/ftp/trends/temp/hansen/gl_land_ocean.txt, Figure 1(a)). We did not use the data on global temperature during 1850-1880 because of their large uncertainty (see e.g. [11] [12]). The observed temperature shows monotonic increase, determined by its linear trend, for ca $0.95^{\circ} \mathrm{C}$ over $1880-2015$ (see Figure 1(a)).

2) We modeled the global temperature with the less intricate autoregressive process of the second order $(\operatorname{AR}(2))$.

3) We adjusted our model so that the simulated signal reproduced the following statistical properties of the actual temperature record: 


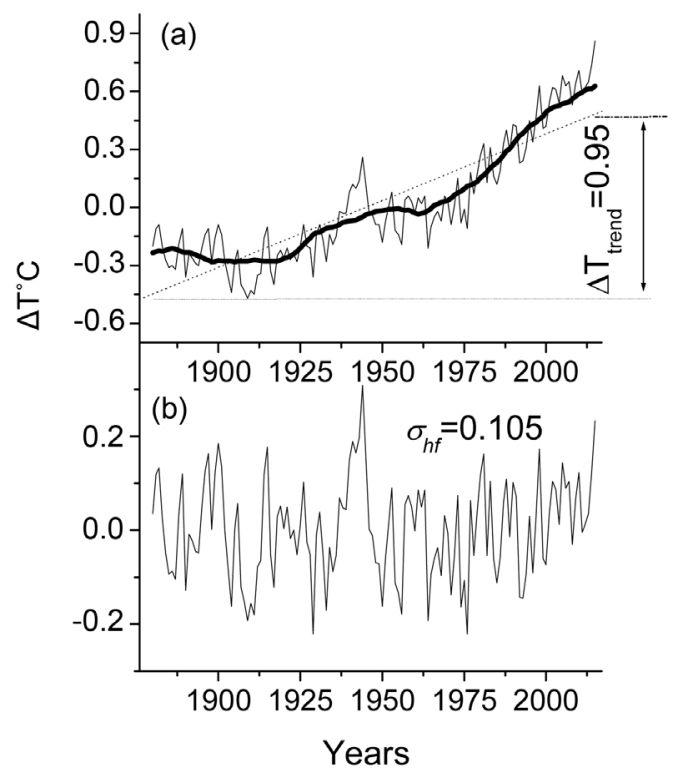

Figure 1. (a) The observed global temperature anomaly (thin line), its 30-year average (thick line), linear trend (dash-dot line); (b) High-frequency fluctuations of the observed global temperature (30-year average is subtracted). $\sigma_{h f}$ is the standard deviation of high-frequency temperature variability. $\Delta T t_{\text {rend }}$-is the linear increase of instrumental temperature during 1880-2015.

a) coefficient of linear dependence of $\Delta T(t-1)$ on $\Delta T(t)\left(\alpha_{1}^{i}\right)$;

b) coefficient of linear dependence of $\Delta T^{i}(t-2)$ on $\Delta T(t)\left(\alpha_{2}^{i}\right)$;

c) standard deviation of high-frequency temperature variability $\left(\sigma_{h f}^{i}\right)$-difference between the raw $\Delta T^{i}$ and the $\Delta T^{i}$ value smoothed by 30 years. All these properties can be reliably estimated using 135 year time series (see Figure 1(b), Figure 2). They are $\alpha_{1}^{i}=0.940, \alpha_{2}^{i}=0.906, \sigma_{h f}^{i}=0.105^{\circ} \mathrm{C}$. We simulated long time series that have the same values $\alpha_{1}, \alpha_{2}, \sigma_{h f}$ i.e. statistical properties very close to that of the observed time series of temperature. We examine them in order to determine how often the warming episodes similar to what is observed during 1880-2015 can occur. For this purpose we generated a number of artificial stochastic time series of length 1000 years, each of which was an autoregressive process of the second order (see Formula (1)). Coefficients $\phi_{1}, \phi_{2}$ and variance of white noise $\sigma_{\varepsilon}^{2}$ were determined so that the mean parameters $\alpha_{1}^{m}, \alpha_{2}^{m}, \sigma_{h f}^{m}$ of the modeled time series were equal to that of the observed instrumental record.

\section{Results and Discussion}

We performed statistical experiments with three different AR(2) processes of the 1000 years length. Their properties are detailed in Table 1 . We looked for time intervals of 135 years length during which the modeled temperature shows linear increase for $0.95^{\circ} \mathrm{C}$ or more-the natural global warming (NGW) events. We used 

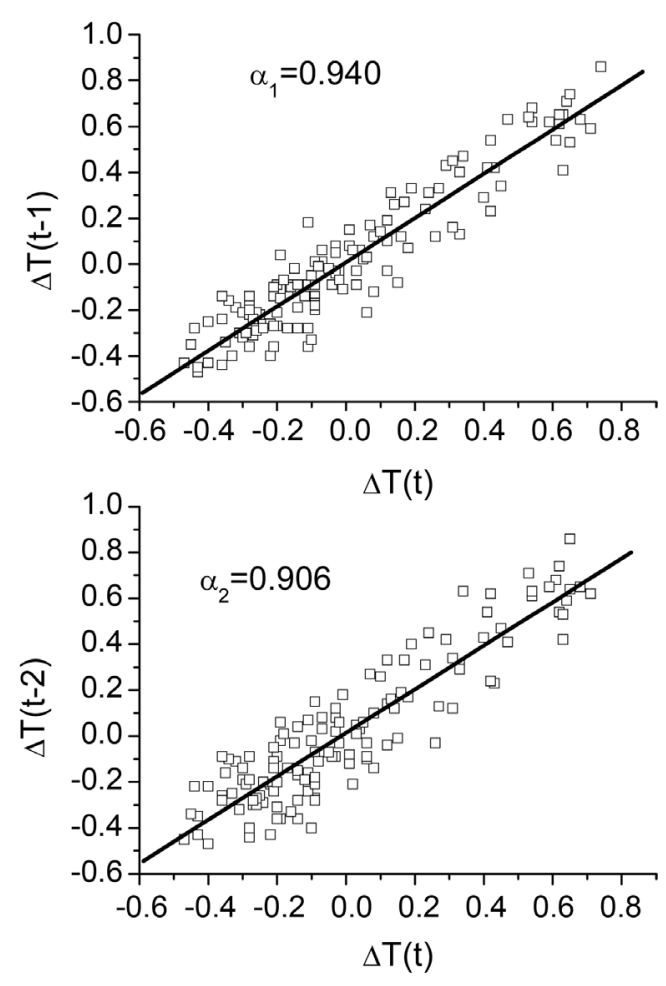

Figure 2. (a) Dependence of $\Delta T(t-1)$ on $\Delta T(t)$ for instrumental temperature (1880-2015); (b) Dependence of $\Delta T(t-2)$ on $\Delta T(t)$ for instrumental temperature. Angles of inclination determine coefficients $\alpha_{1}^{i}, \alpha_{2}^{i}$.

Table 1. Results of statistical examination of frequency occurrence of NGW events.

\begin{tabular}{cccccccccc}
\hline & $\phi_{1}$ & $\phi_{2}$ & $\begin{array}{c}\sigma_{\varepsilon}^{2} \\
\left({ }^{\circ} \mathrm{C}\right)^{2}\end{array}$ & $\alpha_{1}^{m}$ & $\alpha_{2}^{m}$ & $\begin{array}{c}\sigma_{h f}^{m} \\
\left({ }^{\circ} \mathrm{C}\right)\end{array}$ & $N_{1}$ & $N_{2}$ & $N_{3}$ \\
\hline Process 1 & 0.90 & 0.062 & 0.0052 & 0.943 & 0.905 & 0.106 & 351 & 33 & 2 \\
Process 2 & 0.80 & 0.165 & 0.0059 & 0.944 & 0.909 & 0.106 & 556 & 72 & 4 \\
Process 3 & 0.70 & 0.265 & 0.0067 & 0.936 & 0.908 & 0.106 & 617 & 80 & 5 \\
\hline
\end{tabular}

2000 simulations for each kind of $\mathrm{AR}(2)$ process (Table 1).

In Table $1 \phi_{1}, \phi_{2}$ and $\sigma_{\varepsilon}^{2}$ are autoregressive coefficients and variance of white noise, which were used for modeling of time series (see Formula (1)). $\alpha_{1}^{m}$ and $\alpha_{2}^{m}$ are coefficients of linear dependence of the modeled temperatures $\Delta T^{m}(t-1)$ and $\Delta T^{m}(t-2)$ on $\Delta T^{m}(t)$, averaged over all 2000 simulations. $\sigma_{h f}^{m}$ is standard deviation of high-frequency variability of the modeled temperature, averaged over all 2000 simulations. It is evident from Table 1 that statistical properties of the simulated temperatures were actually very similar to that of the observed data set. $N_{1}$ is the number of cases in which one NGW episode took place during 1000 years. $N_{2}$ and $N_{3}$ are numbers of cases with two and three such events. The case of the simulated temperature which has two NGW episodes during 1000 years is shown in Figure 3. Statistical experiments performed using three autoregressive processes, which have statistical characteristics close to that 


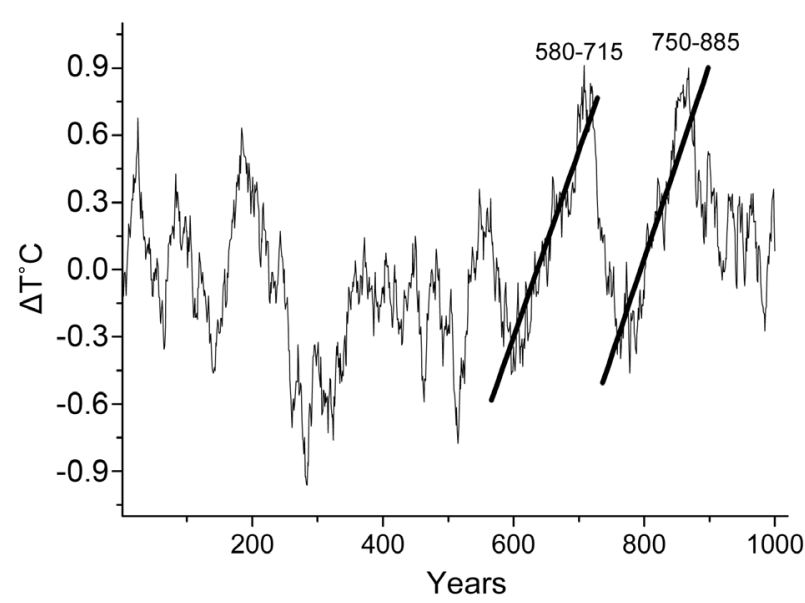

Figure 3. Simulated temperature series $\left(\phi_{1}=0.90, \phi_{2}=0.062\right.$ and $\left.\sigma_{\varepsilon}^{2}=0.0052\left({ }^{\circ} \mathrm{C}\right)^{2}\right)$ with two NGW events. Figures show time intervals during which NGW event took place.

of the instrumental temperature, showed that the frequency of occasion of NGW episodes is $0.19-0.35$ per 1000 years. Therefore their return period is $2849-5180$ years (one event per 2849-5180 years).

Thus, in frame of the used AR(2) model of climatic process the global warming of the last 135 years can very unlikely be fully explained by natural fluctuations.

Then we estimated probability of the part of the GW that was induced by intrinsic climatic variability. We repeated the statistical experiment but with the amplitude of temperature rise of $0.5^{\circ} \mathrm{C}$ during 135 years-the Half Global Warming (HGW) episode. We found that the frequency of HGW events is $2.13-2.34$ per 1000 years and their return period is $426-469$ years. As to events analyzed by Privalsky and Fortus [10] (rise of temperature for $0.5^{\circ} \mathrm{C}$ during 65 years) we estimated their return period as ca 280 years that is less than determined in [10] (489 years). These results testify that inherent variations of climatic system could contribute to the GW appreciably. If the GW is at least partly a result of natural variability of the climatic system this warm fluctuation might continue in the next few decades. Actually, we reveal that the frequency of warm episodes with the amplitude of temperature rise of $0.6^{\circ} \mathrm{C}$ during 165 years is $1.5-1.6$ per 1000 years.

\section{Conclusion}

Numerical experiments with artificial signals (second order random processes), which have important statistical properties similar to that of the observed time series of temperature (1850-2015), indicate that the return period of climatic events analogous to the current GW (linear increase of temperature for $0.95^{\circ} \mathrm{C}$ during 135 years) is $2849-5180$ years. Correspondingly, the probability that the current global terrestrial temperature is going through the NGW episode is 0.026 0.047 . This shows that the GW unlikely could be fully explained by natural variability of temperature. Therefore it is reasonable to regard the GW as a phenomenon exceptional from the point of view of intrinsic climatic oscillations, which need an additional external forcing factor for explanation. On the other 
hand, the statistical experiments showed that an appreciable part of the GW might be a result of natural fluctuations of climatic system. It was found that that the return period of climatic events with $0.5^{\circ} \mathrm{C}$ warming during 135 years is less than 500 years. Thus, the probability that the half of the contemporary GW is produced by natural random oscillations of temperature is more than 0.25 . Emission of greenhouse gases (carbon dioxide, methane, nitrous oxide) most likely is another possible contributor to the GW of the last centuries [1] [2] [13]. Changes in the solar radiation at the Earth's surface (global brightening) might be important source of the warming of the last decades [14]. However, our results show that the contribution of these external factors (including greenhouse effect) to the GW could be less than is often believed [1] [2].

\section{Acknowledgements}

The work of M. G. Ogurtsov was partly supported by the program of the Presidium of RAS No 7 and RFBR grant 16-02-00090.

\section{References}

[1] Intergovernmental Panel on Climate Change (IPCC) (2007) In: Solomon, S., Dahe, Q., Manning, M., et al., Eds., Climate Change 2007: The Physical Science Basis, Cambridge University Press, UK, 996 p.

[2] Intergovernmental Panel on Climate Change (IPCC) (2013) Summary for Policymakers. In: Stocker, T.F., Qin, D., Plattner, G.-K., Tignor, M., Allen, S.K., Boschung, J., Nauels, A., Xia, Y., Bex, V. and Midgley, P.M., Eds., Climate Change, the Physical Science Basis. Contribution of Working Group I to the Fifth Assessment Report of the Intergovernmental Panel on Climate Change, Cambridge University Press, Cambridge, UK and New York, NY, USA. 30 p.

[3] Soon, W., Connolly, R. and Connolly, M. (2015) Re-Evaluating the Role of Solar Variability on Northern Hemisphere Temperature Trends since the 19th Century. Earth-Science Reviews, 150, 409-452. https://doi.org/10.1016/j.earscirev.2015.08.010

[4] Zhao, X.H. and Feng, X.S. (2014) Periodicities of Solar Activity and the Surface Temperature Variation of the Earth and Their Correlations. Chinese Scientific Bulletin, 59, 1284-1292.

[5] Harde, H. (2014) Advanced Two-Layer Climate Model for the Assessment of Global Warming by CO2. Open Journal of Atmospheric and Climate Change, 1, 1-50. https://doi.org/10.15764/ACC.2014.03001

[6] Lüdecke, H.-J., Hempelmann, A. and Weiss C.O. (2013) Multi-Periodic Climate Dynamics: Spectral Analysis of Long-Term Instrumental and Proxy Temperature Records. Climate Past, 9, 447-452. https://doi.org/10.5194/cp-9-447-2013

[7] Scafetta, N. (2010) Empirical Evidence for a Celestial Origin of the Climate Oscillations and Its Implications. Journal of Atmospheric and Solar-Terrestrial Physics, 72, 951-970. https://doi.org/10.1016/j.jastp.2010.04.015

[8] Scafetta, N. (2012) Multi-Scale Harmonic Model for Solar and Climate Cyclical Variation throughout the Holocene Based on Jupiter-Saturn Tidal Frequencies Plus the 11-Year Solar Dynamo Cycle. Journal of Atmospheric and Solar-Terrestrial Physics, 80, 296-311. https://doi.org/10.1016/j.jastp.2012.02.016

[9] Swanson, K.L. and Tsonis, A.A. (2009) Has the Climate Recently Shifted? Geophysical Research Letters, 36, L06711. https://doi.org/10.1029/2008GL037022 
[10] Privalsky, V. and Fortus, M. (2011) Miscellanea on Possible Causes of the Global Warming. Theory of Probability and Its Applications, 56, 313-317. https://doi.org/10.1137/S0040585X97985418

[11] Folland, C.K., Rayner, N.A., Brown, S.J., Smith, T.M., Shen, S.S., Parker, D.E., Macadam, I., Jones, P.D., Jones, R.N., Nichols, N. and Sexton, D.M.H. (2001) Global Temperature Change and Its Uncertainties since 1861. Geophysical Research Letters, 28, 2621-2624. https://doi.org/10.1029/2001GL012877

[12] Morice, C.P., Kennedy, J.J., Rayner, N.A. and Jones, P.D. (2012) Quantifying Uncertainties in Global and Regional Temperature Change Using an Ensemble of Observational Estimates: The HadCRUT4 Dataset. Journal of Geophysical Research. 117, D08101. https://doi.org/10.1029/2011JD017187

[13] Etminan, M., Myhre, G., Highwood, E.J. and Shine, K.P. (2016) Radiative Forcing of Carbon Dioxide, Methane, and Nitrous Oxide: A Significant Revision of the Methane Radiative Forcing, Geophysical Research Letters, 43, 12614-12623. https://doi.org/10.1002/2016GL071930

[14] Ogurtsov, M., Lindholm, M. and Jalkanen, R. (2012) Background Solar Irradiance and the Climate of the Earth in the End of the 20th Century. Atmospheric and Climate Sciences, 2, 191-195. https://doi.org/10.4236/acs.2012.22019

\section{Submit or recommend next manuscript to SCIRP and we will provide best service for you:}

Accepting pre-submission inquiries through Email, Facebook, LinkedIn, Twitter, etc. A wide selection of journals (inclusive of 9 subjects, more than 200 journals)

Providing 24-hour high-quality service

User-friendly online submission system

Fair and swift peer-review system

Efficient typesetting and proofreading procedure

Display of the result of downloads and visits, as well as the number of cited articles

Maximum dissemination of your research work

Submit your manuscript at: http://papersubmission.scirp.org/

Or contact acs@scirp.org 